\title{
LIGHT ALKANE (MIXED FEED) SELECTIVE DEHYDROGENATION USING BI- METALLIC ZEOLITE SUPPORTED CATALYST
}

\author{
Zeeshan Nawaz ${ }^{1 *}$, Qing Shu ${ }^{1}$, Shahid Naveed ${ }^{2}$ and Fei Wei ${ }^{1}$ \\ ${ }^{1}$ Beijing Key Laboratory of Green Chemical Reaction Engineering and Technology (FLOTU), \\ Department of Chemical Engineering, Tsinghua University, Beijing 100084, China \\ ${ }^{2}$ Department of Chemical Engineering, University of Engineering and Technology, Lahore \\ 54890, Pakistan
}

(Received December 8, 2008; revised April 13, 2009)

\begin{abstract}
Light alkanes are the important intermediates of many refinery processes and their catalytic dehydrogenation gives corresponding alkenes. The aim behind this experimentation is to investigate reaction behavior of mixed alkanes during direct catalytic dehydrogenation and emphasis has been given to enhance propene. Bi-metallic zeolite supported catalyst Pt-Sn/ZSM-5 was prepared by sequentional impregnation method and characterized by BET, EDS and XRD. Direct dehydrogenation reaction is highly endothermic and its conversion is thermodynamically limited. Results showed that the increase in temperature increases the conversion to some extent but there is no overall effect on selectivity of propene. Increase in time-on-stream (TOS) remarkably improves propene selectivity at the expense of lower conversion. The performances of bimetallic zeolite based catalyst largely affected by coke deposition. The presence of butane and ethane adversely affected propane conversion. Optimum propene selectivity is about $48 \%$, obtained at $600{ }^{\circ} \mathrm{C}$ and time-on-stream $10 \mathrm{~h}$.
\end{abstract}

KEY WORDS: Light olefins, Mixed feed, Propene, Selective dehydrogenation, Zeolite ZSM-5

\section{INTRODUCTION}

The demand for propene is dominated by the polypropylene industry [1]. Traditional processes are unable to meet the growing demand of propene [2], e.g. co-production of propene from steam cracking [3]. In FCC unit's propene yield is also limited, even with state of the art advancements, like downer reactors and novel selective catalysts [1-6]. Therefore in recent days, much attention has been focused on on-purposed propene technologies. Alkanes are the world's most abundant organic resource and probably the versatile class of feedstock for commodity scale organic chemical syntheses. Some recent developments like olefin cracking, methanol to propene (MTP), methane to olefins (MTO), etc. were also reported light alkanes as significant by-product $[7,8]$. Therefore dehydrogenation can be considered as viable option for increasing the supply of propene [9]. This technology can use stand alone, particularly in the areas where cheap alkane feedstock is easily available such as Africa and Middle East.

The high endothermicity of light alkane dehydrogenation reaction is the key factor involved in catalyst design. Previously much attention has been given to oxidative dehydrogenation because of its advantages like non-thermodynamic limited reaction and high conversion. But owing to very adverse HAZOP problems and very low propene selectivity at high conversion, this process can not get fame [10-14], while the direct propane dehydrogenation is endothermic and having low conversion.

Platinum based catalysts shows better dehydrogenation ability, therefore many possible combinations were tried to enhance catalytic activity and stability. Effect of reaction conditions and time on stream analysis of $\mathrm{Pt} / \mathrm{Al}_{2} \mathrm{O}_{3}$ and $\mathrm{Pt}-\mathrm{Sn} / \mathrm{Al}_{2} \mathrm{O}_{3}$ catalysts were pointed out the bimetallic Pt-Sn catalyst is more resistant to deactivation [14-18]. Numerous works has been reported about further improvement and stability of Pt-Sn catalysts using alkali metals such as

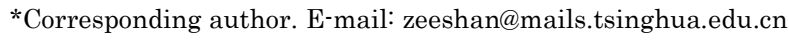


$\mathrm{Li}, \mathrm{Ba}, \mathrm{K}, \mathrm{Ca}, \mathrm{Na}$, etc. $[19,20]$. Also many researchers focus on utilization of non-acidic and thermally stable supports, such as $\mathrm{MgAl}_{2} \mathrm{O}_{4}$ and $\mathrm{ZnAl}_{2} \mathrm{O}_{4}$ [20, 21]. However, the overall dehydrogenation performance of Pt-Sn catalysts is still not satisfactory because of quick deactivation and desired product selectivity. The reason for poor catalytic performance is sate forwardly, platinum particles aggregation and carbon deposition.

From last decade zeolites were extensively used as catalysts in petrochemical industries and much work has been reported for its characterization and applications [22-25]. Grasselli et al., Yiwei et al. and Zeeshan et al. studied propane dehydrogenation using PtSn/ZSM-5 catalyst (prepared by co-impregnation) reported better stability than $\mathrm{Pt}-\mathrm{Sn} / \mathrm{Al}_{2} \mathrm{O}_{3}$, but more focus on catalysis characterization [26-29]. The bimetallic catalyst supported by different carrier's that results variant interactions between metals itself and support, which affect the overall catalytic performance. Most of the authors reported poor reaction satiability and argued that it is due to carbon deposition, but on the other hand justify their work with incomplete picture. Nevertheless, no investigation has focused the effect of mixed alkane feed or unavoidable impurities present in feed using bi-metallic zeolite supported catalyst. In this paper the influence of operating parameters on direct dehydrogenation of mixed alkane feed using bi-metallic catalyst (prepared by sequential impregnation method) and reaction behavior is examined.

\section{EXPERIMENTAL}

\section{Feedstock}

Mixed alkane feed was provided by Ling Gas, Beijing, China, and used in the present investigation to study reaction dynamics in a micro-reactor. The contents of feed mixture were analyzed by online gas chromatography (Figure 1).

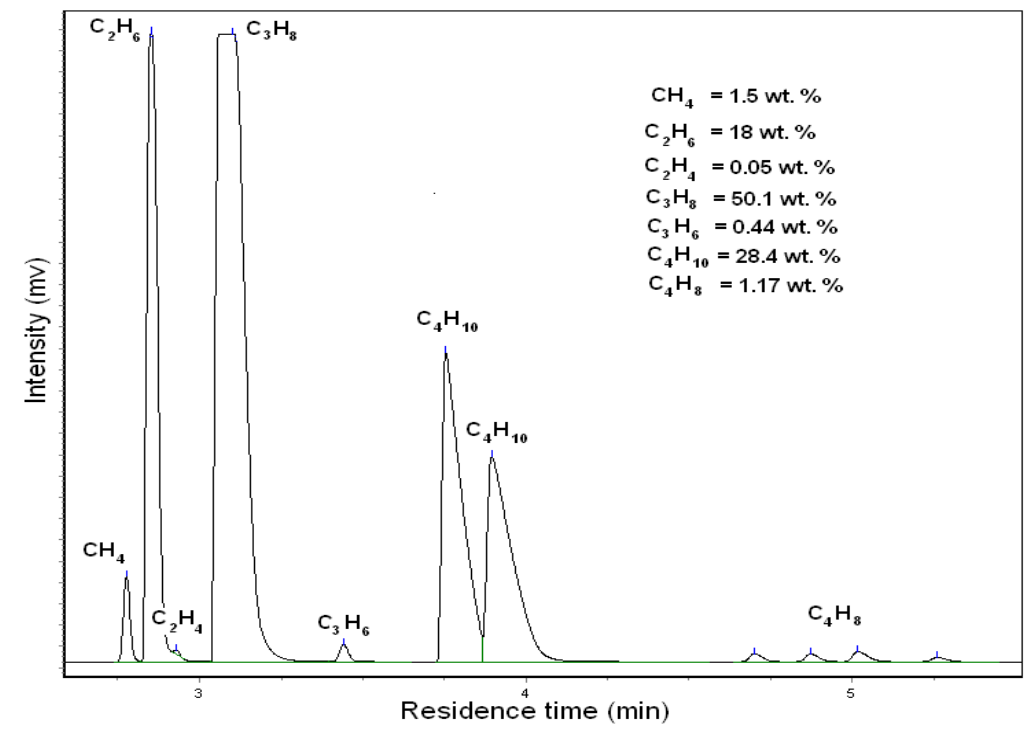

Figure 1. Mixed alkane feed composition. 


\section{Catalyst preparation}

The monometallic catalyst of $0.5 \mathrm{wt} . \% \mathrm{Pt}$ was prepared by impregnation of the powder H-ZSM5 of $\mathrm{Si} / \mathrm{Al}=140$ [29], in aqueous solutions of $0.03 \mathrm{M} \mathrm{H}_{2} \mathrm{PtCl}_{6}$ at $60{ }^{\circ} \mathrm{C}$. HZSM-5 has specific surface area $354.1 \mathrm{~m}^{2} / \mathrm{g}$ (provided by Nankai Catalyst Company, Tianjin, China). Afterward impregnated sample was dried at $100{ }^{\circ} \mathrm{C}$ for $4 \mathrm{~h}$ and calcined at $500{ }^{\circ} \mathrm{C}$ in Muffle furnace for 4 h. In the preparation of bimetallic Pt-Sn/ZSM-5 catalyst, first powder H-ZSM-5 zeolite was impregnated with $0.16 \mathrm{M} \mathrm{SnCl}_{2} \cdot 2 \mathrm{H}_{2} \mathrm{O}$ at $80{ }^{\circ} \mathrm{C}$ to make 1 wt. $\% \mathrm{Sn}$ in the catalyst and dried at $100{ }^{\circ} \mathrm{C}$ for $4 \mathrm{~h}$. After completely dried, the catalysts were calcined at $500{ }^{\circ} \mathrm{C}$ for $4 \mathrm{~h}$ and impregnated again with 0.5 wt. \% Pt solution of $0.03 \mathrm{M} \mathrm{H}_{2} \mathrm{PtCl}_{6}$ at $60{ }^{\circ} \mathrm{C}$, followed by drying [29]. Then both mono and bi-metallic catalysts were crushed and dechlorinated at $480{ }^{\circ} \mathrm{C}$ for $4 \mathrm{~h}$ with steam. Prior to the reaction tests, all of catalysts samples were reduced in $\mathrm{H}_{2}$ environment at $510{ }^{\circ} \mathrm{C}$ over night.

\section{Catalyst characterization}

The metallic contents of ZSM-5 supported catalyst were obtained by EDS (Energy Dispersive Spectrum) using scanning electron microscope (JSM 7401F at FLOTU, Tsinghua University, Beijing, China) and results are given in Table 1. BET Surface areas of catalyst samples were determined by $\mathrm{N}_{2}$ physi-sorption using an automatic analyzer (NOVA 4000, Quantachrome, USA). The samples were outgassed for $2 \mathrm{~h}$ under vacuum at $350{ }^{\circ} \mathrm{C}$, prior to adsorption. Then the surface areas of each catalyst were calculated using BET equation and results are shown in Table 1. The X-ray diffraction (XRD) patterns of each catalyst were obtained on a Philips Powder X-ray Diffractometer (USA). The X-ray tube was operated at $40 \mathrm{kV}$ and its scanning rate was $5 \% \mathrm{~min}$. The K $\alpha$ radiation of diffracted beam monochromator was selected and angular range from $5^{\circ}$ to $35^{\circ}$ was recorded using step scanning. XRD pattern of catalysts are shown in Figure 2.

Table 1. Metallic content and BET surface area of ZSM-5 supported catalysts.

\begin{tabular}{|l|c|c|c|}
\hline Catalyst & Pt content (wt. \%) & Sn content (wt. \%) & $\mathrm{S}_{\mathrm{BET}}\left(\mathrm{m}^{2} / \mathrm{g}\right)$ \\
\hline ZSM-5 (SAR = 140) & - & - & 354.1 \\
\hline Pt/ZSM-5 (SAR = 140) & 0.47 & - & 346.9 \\
\hline Pt-Sn/ZSM-5 (SAR = 140) & 0.41 & 0.92 & 341.9 \\
\hline
\end{tabular}

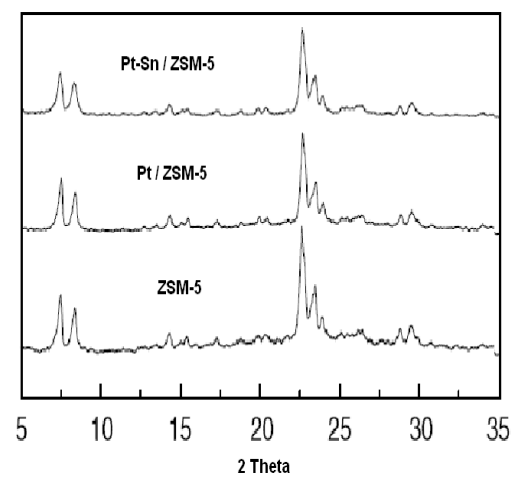

Figure 2. XRD data of calcined catalysts of $\mathrm{SAR}(\mathrm{Si} / \mathrm{Al})=140$. 
Recently, many ZSM-5 supported combinations of varying Pt and Sn contents were characterized and it has been reported that large surface area provided by zeolite catalysts in comparison with amorphous $\mathrm{Al}_{2} \mathrm{O}_{3}$ supported catalyst suppress coke formation [28, 30]. XRD of pure ZSM-5 and prepared combinations indicates that its structure remains stable after sequential impregnation. XRD pattern also proves that $\mathrm{Pt}$ is well dispersed in the presence of $\mathrm{Sn}$ promoter, while by increasing Sn content ZSM-5 crystallinity decreases [29, 31]. All the Pt exist on the surface of catalyst owing to larger dynamic diameter, i.e. 1.4-2 nm [32] and promoted hydrogen abstraction.

\section{Catalyst performance analysis}

Propane dehydrogenation experiment is carried out in a continuous flow quartz fixed-bed reactor $(6 \mathrm{~mm}$ in diameter, $100 \mathrm{~mm}$ in length) with a controlled temperature setup at atmospheric pressure and experimental setup is shown in Figure 3. The measured amount of catalyst was put into the reactor to obtain desired WHSV, i.e. $6 \mathrm{~h}^{-1}$ and reaction mixture was composed of $\mathrm{H}_{2}$ and $\mathrm{C}_{3} \mathrm{H}_{8}$, with $\mathrm{H}_{2} / \mathrm{C}_{3} \mathrm{H}_{8}$ molar ratio 0.25 . The catalyst was previously reduced over night with $\mathrm{H}_{2}(8 \mathrm{~mL} / \mathrm{min})$ at $510{ }^{\circ} \mathrm{C}$. The reaction behaviour was analyzed between temperature range $525-625{ }^{\circ} \mathrm{C}$ and time-on-stream 1-10 h. The products distribution was analyzed by online gas chromatography (GC-7890II, with a 50-m PLOT $\mathrm{Al}_{2} \mathrm{O}_{3}$ capillary column and FID detector, USA). The conversion of feed, product yield and product selectivities are in terms of weight percentage.

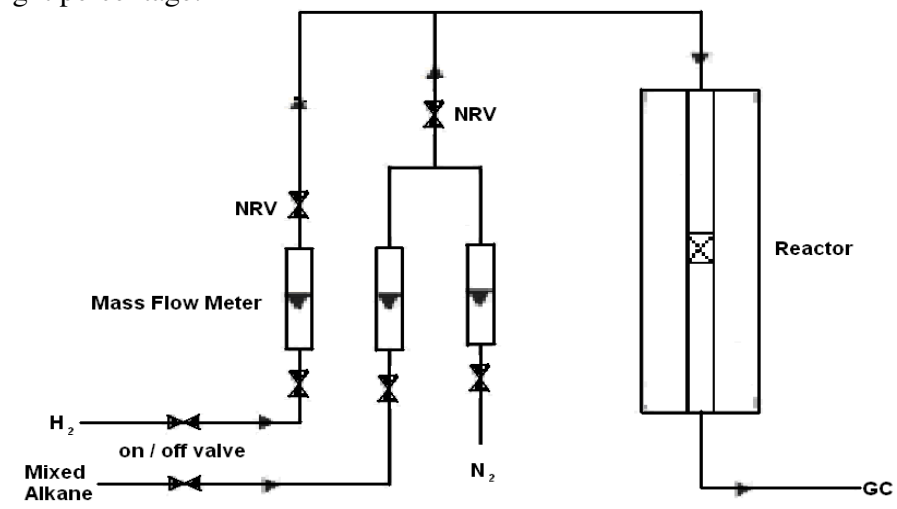

Figure 3. Experimental setup for dehydrogenation.

\section{RESULTS AND DISCUSSION}

Direct catalytic dehydrogenation is highly endothermic and activation energy requirement increases with the decrease in carbon chain [33]. The reaction dynamics makes this reaction more complex; as higher reaction temperature favors dehydrogenation while on the other hand cracks desired product (propene) into unwanted fragments. But their equilibrium conversion strongly effected with the presence of impurities in the feed. At $574{ }^{\circ} \mathrm{C}$ and atmospheric pressure the pure propane conversion is thermodynamically limited to $29.7 \%$ [34]. Also in refinery feedstock's its difficult to find $100 \%$ pure propane feed for dehydrogenation. Therefore in the present study we analyze the catalytic activity and reaction dynamics of overall dehydrogenation using mixed alkane feed.

Zeolite's have well-defined ring structure and shape selectivity is their distinct feature. ZSM-5 possesses 10-membered ring channels, that hinder coke formation and in this way it

Bull. Chem. Soc. Ethiop. 2009, 23(3) 
improves catalytic stability. Lower catalytic acidity enhances the reaction stability is due to reduction in coke formation. The acidity of zeolite is controlled by manipulating the $\mathrm{Si} / \mathrm{Al}$ ratio $[29,34]$. That's why we select H-ZSM-5 of SAR= 140 and its dechlorination with steam at 480 ${ }^{\circ} \mathrm{C}$ this ratio further increases. Before steaming FAL (framework $\mathrm{Al}$ ) are mostly in pair those contributed to reaction but steaming converts FAI to EFAL (ex-framework Al) and in overall active acid sites decreased [35, 36]. Increase in Sn content of Pt-Sn/ZSM-5 catalyst enhances alkene selectivity but seems to be no effect on dehydrogenation rate [28, 29]. Bi-metallic zeolites supported catalyst (Pt-Sn/ZSM-5) was investigated over the range of temperatures and TOS values along with Pt/ZSM-5 and ZSM-5 catalysts. Previously same catalytic combination prepared by co-impregnation method was reported by Yiwei [28, 29], and used after palletization with alumina. In present experimentation we find that the results of sequentional impregnation method are better than co-impregnation and also we used pure catalyst without alumina binder.

Here we find that bi-metallic zeolite based catalyst conversion is for better than monometallic ZSM-5 and simple ZSM-5 (see Figure 4 and 5). The feed conversion and selectivity of products were calculated using following relationships (equation 1 and 2 , respectively). Dehydrogenation ability of simple ZSM-5 (SAR = 140) is unacceptably low, while the activity of monometallic catalyst (Pt/ZSM-5) is slightly better than ZSM-5, but not impressive. The conversion of bimetallic catalyst is far better and increases both initial and final conversions to $57 \%$ and $30 \%$, respectively. Significant improvement in conversion is observed at $600{ }^{\circ} \mathrm{C}$ and their deactivation rate is much stable. Highest propene selectivity about $55 \%$ was observed on bimetallic catalyst at $550{ }^{\circ} \mathrm{C}$ owing to lower conversion. Almost similar conversion of feed on bimetallic catalysts is obtained at $600{ }^{\circ} \mathrm{C}$ and $625{ }^{\circ} \mathrm{C}$ with better initial selectivity. Final selectivities of bimetallic catalysts decrease because most of the propene cracks further at higher temperatures. Also the combination of higher conversion with lower desired product selectivity is ridiculous. Therefore the optimum operating temperature is about $600{ }^{\circ} \mathrm{C}$. Increase in temperature not only increase the conversion of feed to some extent but also modify the product distribution remarkably. Propene selectivity increases with increase in TOS at the expense of lower propane conversion. The spillover decrease in dehydrogenation rate is due to coke deposition.

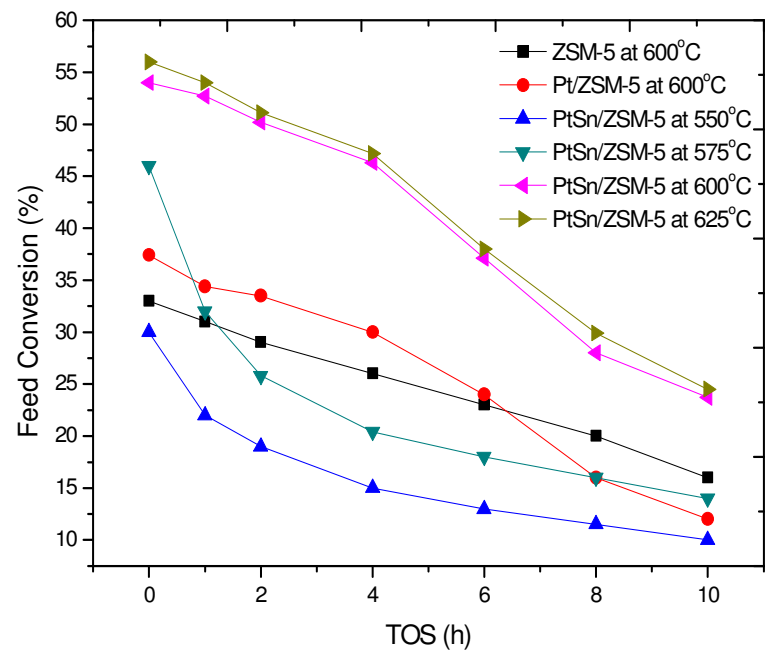

Figure 4. Feed conversion of different catalysts at WHSV $=6 \mathrm{~h}^{-1}$.

Bull. Chem. Soc. Ethiop. 2009, 23(3) 


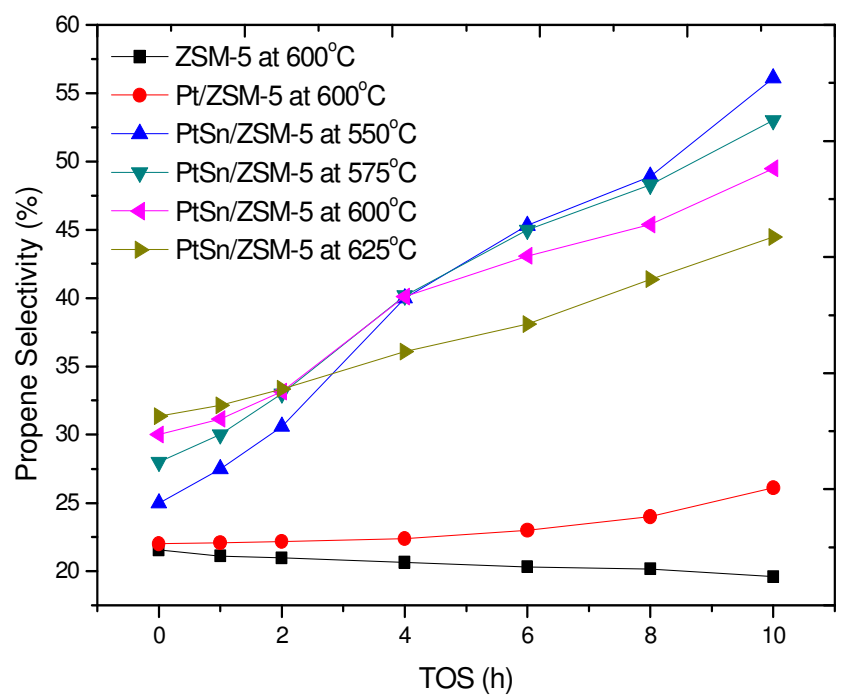

Figure 5. Propene selectivity of different catalysts at WHSV $=6 \mathrm{~h}^{-1}$.

Conversion $(\%)=\frac{(\text { content of components in feedstock })-(\text { content of all components in product }) \times 100}{}$

Content of all components in feedstock

(content of alkenes in product) - (content of alkenes in feedstock) x 100

Selectivity of alkenes $(\%)=\frac{\text { Overall conversion }(\%)}{(\text { content }}$

Activation energy requirements for dehydrogenation decreases with the increase in carbon chain [33] and it can be observed from product distribution in Figure 6. Butane cracks quickly over bi-metallic zeolite supported catalyst comparative to propane and ethane. This phenomenon was more enhanced with the increase in TOS. Initial experimental data shows that most of the butane converts to ethane. Therefore the total olefin selectivity is decreased at higher temperatures. Initially the methane and ethane yields are high, but sudden after an hour, product distribution proceeds towards better olefin's selectivity. The propene yield is observed to be constant with TOS, while the total olefin yield increases with TOS. The stable methane yield suggests that most of the butane converts to propene and methane. At higher TOS values the catalytic activity was reduced much but its ability to crack butane did not drop, therefore methane yield remains constant.

The presence of ethane and butane has significant influence on product distribution and adversely affect propane conversion in particular. Also some propane and propene may be converted to ethane, ethene and methane. While some butane converts to ethane and ethene depending upon the carbenium ion mechanism and then it's more difficult to crack ethane. Therefore increase in TOS converts ethane to coke precursors. It's also not feasible to get higher propene selectivity by means of increasing temperature. At higher temperature the reaction dynamics scenario is quite different. But increase in time-on-stream largely increase ethene content not by converting ethane but from other sources. Therefore the major feed contents of mixed alkane feed make the process more complex and change reaction dynamics. Furthermore it's very clear from the results shown in Figure 6 that Pt-Sn/ZSM-5 also selectively converts ethane and butane to propene.

Bull. Chem. Soc. Ethiop. 2009, 23(3) 


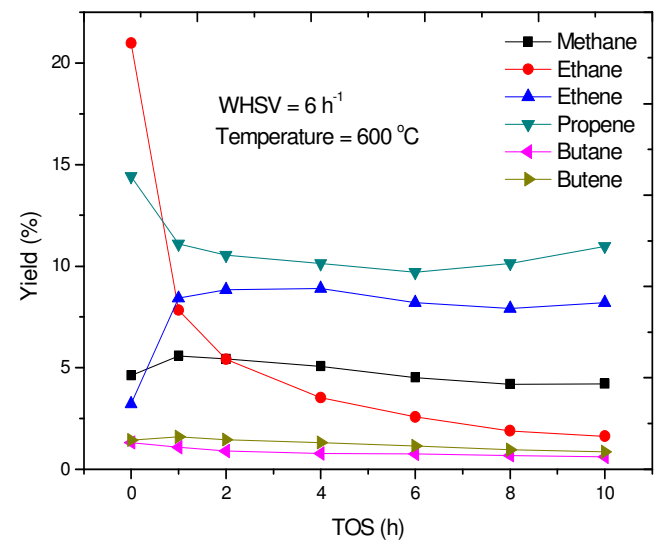

Figure 6. Product distribution of bi-metallic catalyst Pt-Sn/ZSM-5.

\section{CONCLUSIONS}

The present investigation is very helpful to explore the process difficulties and understand reaction dynamics of mixed alkane feed dehydrogenation. Higher propylene selectivity is noted at higher time-on-stream at the cost of lower conversion. Bi-metallic zeolite supported catalyst (Pt-Sn/ZSM-5) promoters dehydrogenation in effective manner than mono-metallic and zeolite it self. The catalytic performance adversely effected at higher temperatures; as at $625{ }^{\circ} \mathrm{C}$ and TOS $10 \mathrm{~h}$ the propene selectivity is limited to about $43 \%$, i.e. $13 \%$ less that at $600{ }^{\circ} \mathrm{C}$. Also no increment in dehydrogenation rate and propene yield was observed with the increase in temperature. While highest propene selectivity is obtained at $550{ }^{\circ} \mathrm{C}$ and TOS $10 \mathrm{~h}$ at $10 \mathrm{wt}$. \% overall feed conversion. At optimum temperature about $600{ }^{\circ} \mathrm{C}$ and $\operatorname{TOS} 10 \mathrm{~h}$, the initial and final propene selectivity is 30 and $50 \mathrm{wt}$ \% , respectively. The major share of feed conversion is butane. The presence of butane causes the problems of high initial ethane selectivity rather than propene and also reduces propane conversion.

\section{AKNOWLEDGEMENTS}

Authors are very thankful to Higher Education Commission, Islamabad, Pakistan, for financial support (under Overseas Scholarship Scheme) and technical facilities provided by Beijing Key Laboratory of Green Chemical Reaction Engineering and Technology (FLOTU), Tsinghua University, Beijing, China.

\section{REFERENCES}

1. Ladwig, P.K.; Asplin, J.E.; Stuntz, G.F.; Wachter, W.A.; Henry, B.E. US Patent 2000, No. 6069287.

2. Corma, A.; Melo, F.V.; Sauvanaud, L.; Ortega, F. Catal. Today 2005, 107-108, 699.

3. Johnson, L.D.; Nariman, E.K.; Ware, A.R. US Patent 2001, No. 6222087.

4. Stiffens, T.R.; Ladwig, P.K.; Process for selectively producing light olefins, US Patent 2002, No. 6455750.

5. Thang, X. PhD Desertation, Tsinghua University, Beijing, China, 2008.

6. Andersen, J.; Bakas, S.; Kvisle, S.; Nilsen, H.R. ERTC Petrochemical Conference, Paris, 2003. 
7. Stauffer, J.E. US Patent 2006, No. 7091391.

8. Rylander, P.N.; Elvers, B.; Rounsaville J.F.; Schulz, G.; Ullmann's Encyclopedia of Industrial Chemistry, VCH Verlagsgesellschaft: Weinheim; 1989; p 494.

9. Barbero, B.P.; Prada S.R.; Cadus, L.E. Latin Amer. Appl. Res. 2005, 35, 273.

10. Kaidong C.; Enrique I.; Alexis T.B. J. Catal. 2000, 192, 197.

11. Rosso, R.D.; Kaddouri, A.; Anouchinsky, R.; Mazzocchia, C.; Gronchi P.; Centola, P. J. Mol. Catal. A: Chem. 1998, 35, 181.

12. Fuchs, S.; Leveles, L.; Seshan, K.; Lefferts, L.; Lemonidou, A.; Lercher, J.A. Topics in Catal. 2001, 15, 169.

13. Jason D.P.; Billy B.B.; Hack-Sung K.; Donggeun K.; Matthew T.S.; Robin R.H.; Peter C.S.; Kenneth, R.P. J. Catal. 2004, 223, 419.

14. Bhasin, M.M.; McCain J.H.; Vora, B.V.; Imai T.; Pujado P.R. App. Catal. A: Gen. 2001, $221,397$.

15. Cortright, R.D.; Hill J.M.; Jams, A.D. Catal. Today. 2000, 55, 213.

16. Homs, L.N.; Leon, J.; Sales, J.; Fierro J.L.G.; Ramirez, P. Appl. Catal. A: Gen. 1999, 189, 77.

17. Kappenstein, C.; Guerin, M.; Lazar, K.; Matusek K.; Paal, Z. J. Chem. Faraday Trans. 1998, 94, 2463.

18. Rodr, G.D.; Sanchez, J.; Arteaga, G. J. Mol. Catal. A: Chem. 2005, 228, 309.

19. Akporiaye, D.; Jensen, S.F.; Olsbye, U.; Rohr, F.; Rytter, E.; Ronnekleiv M.; Spjelkavik, A.I. Ind. Eng. Chem. Res. 2001, 40, 4741.

20. Miguel, S.R.; Jablonski, E.; Castro, A.A.; Scelza, O.A. J. Chem. Tech. Biotech. 2000, 5, 596.

21. Kissin, Y. J. Catal. 1996, 163, 50.

22. Narbeshuber, T.F.; Brait, A.; Seshan, K.; Lercher, J.A. J. Catal. 1997, $172,127$.

23. Fu, Z.H.; Yin, D.L.; Yang, Y.S.; Guo, X.X. Appl. Catal. A: Gen. 1995, 124, 59.

24. Dorado, F.; Romero, R.; Canizares, P. Ind. Eng. Chem. Res. 2001, 40, 3428.

25. Grasselli, R.K.; Stern, D.L.; Tsikoyiannis, J.G. Appl. Catal. A: Gen. 1999, 189, 1.

26. Grasselli, R.K.; Stern, D.L.; Tsikoyiannis, J.G. Appl. Catal. A: Gen. 1999, 189, 9.

27. Yiwei, Z.; Zhou, Y.; Qiu, A.; Wang, Y.; Xu, Y.; Wu, P. Catal. Comm. 2006, 7, 860.

28. Yiwei, Z.; Zhou, Y.; Qiu, A.; Wang, Y.; Xu, Y.; Wu, P. ACTA Phys.-Chim. Sinica 2006, 22, 6.

29. Zeeshan, N.; Tang, X.; Wei, F. Korean J. Chem. Eng. 2009, xxx, xxx (Accepted).

30. Rachapudi, R.; Chintawar, P.S.; Greene, H.L. J. Catal. 1995, 185, 58.

31. Lucas, A.D.; Valverde, J.L.; Sanchez, P.; Dorado, F.; Ramos, M.J. Appl. Catal. A: Gen. 2005, 282, 15.

32. Zygmunt, S.A.; Bootz, B.L.; Miller, A.W.; Curtiss, L.A.; Iton, L.E. 17th North American Catalysis Meeting, Toronto, Canada, 2001.

33. Serge, R. Thermal and Catalytic Processes in Petroleum Refining, Marcel Dekker: New York; 2003; p 14.

34. Barias, O.A.; Holmen, A.; Blekkan, E.A. Catal. Today. 1995, 24, 361.

35. Dedecek, J. Chem. Comm. 2001, 3, 970.

36. Sklenak, S. Angew. Chem. Int. Ed. 2007, 46, 7286. 